Full length article

\title{
Evaluation of biomimetic hyaluronic-based hydrogels with enhanced endogenous cell recruitment and cartilage matrix formation
}

\author{
M.L. Vainieri ${ }^{\mathrm{a}, \mathrm{b}}$, A. Lolli ${ }^{\mathrm{b}}$, N. Kops ${ }^{\mathrm{b}}$, D. D’Atri ${ }^{\mathrm{c}}$, D. Eglin ${ }^{\mathrm{a}}$, A. Yayon ${ }^{\mathrm{d}}$, M. Alini ${ }^{\mathrm{a}}$, S. Grad ${ }^{\mathrm{a}}$, \\ K. Sivasubramaniyan ${ }^{\mathrm{b}}$, G.J.V.M. van Osch ${ }^{\mathrm{b}, \mathrm{e}, *}$ \\ ${ }^{a}$ AO Research Institute Davos, Davos Platz, Switzerland \\ ${ }^{\mathrm{b}}$ Department of Orthopeadics, Erasmus MC, University Medical Center, CN Rotterdam, the Netherlands \\ c Faculty of Biotechnology and Food Engineering, Technion - Israel Institute of Technology, Haifa, Israel \\ d ProCore Ltd., Weizmann Science Park, 7 Golda Meir St., Ness Ziona 70400, Israel \\ e Department of Otorhinolaryngology, Erasmus MC, University Medical Center, CN Rotterdam, the Netherlands
}

\section{A R T I C L E I N F O}

\section{Article history:}

Received 24 June 2019

Revised 6 November 2019

Accepted 7 November 2019

Available online 11 November 2019

\section{Keywords:}

Biomaterials

Cell migration

Osteochondral defect model

Endogenous cell recruitment

Cartilage repair

\begin{abstract}
A B S T R A C T
Biomaterials play a pivotal role in cell-free cartilage repair approaches, where cells must migrate through the scaffold, fill the defect, and then proliferate and differentiate facilitating tissue remodeling. Here we used multiple assays to test the influence of chemokines and growth factors on cell migration and cartilage repair in two different hyaluronan (HA)-based hydrogels. We first investigated bone marrow Mesenchymal Stromal Cells (BMSC) migration in vitro, in response to different concentrations of plateletderived growth factor-BB (PDGF-BB), chemokine ligand 5 (CCL5/RANTES) and stromal cell-derived factor 1 (SDF-1), using a 3D spheroid-based assay. PDGF-BB was selected as most favourable chemotactic agent, and MSC migration was assessed in the context of physical impediment to cell recruitment by testing Fibrin-HA and HA-Tyramine hydrogels of different cross-linking densities. Supplementation of PDGF-BB stimulated progressive migration of MSC through the gels over time. We then investigated in situ cell migration into the hydrogels with and without PDGF-BB, using a cartilage-bone explant model implanted subcutaneously in athymic mice. In vivo studies show that when placed into an osteochondral defect, both hydrogels supported endogenous cell infiltration and provided an amenable microenvironment for cartilage production. These processes were best supported in Fibrin-HA hydrogel in the absence of PDGFBB. This study used an advanced preclinical testing platform to select an appropriate microenvironment provided by implanted hydrogels, demonstrating that HA-based hydrogels can promote the initial and critical step of endogenous cell recruitment and circumvent some of the clinical challenges in cartilage tissue repair.
\end{abstract}

\section{Statement of significance}

The challenge of articular cartilage repair arises from its complex structure and architecture, which confers the unique mechanical behavior of the extracellular matrix. The aim of our research is to identify biomaterials for implants that can support migration of endogenous stem and progenitor cell populations from cartilage and bone tissue, in order to permanently replace damaged cartilage with the original hyaline structure.

Here, we present an in vitro 3D spheroid-based migration assay and an osteochondral defect model, which provide the opportunity to assess biomaterials and biomolecules, and to get stronger experimental evidence of the not well-characterized dynamic process of endogenous cells colonization in an osteochondral defect. Furthermore, the delicate step of early cell migration into biomaterials towards functional

\footnotetext{
* Corresponding author at: Department of Otorhinolaryngology, Erasmus MC, University Medical Center, Wytemaweg 80, 3015 CN Rotterdam, the Netherlands.

E-mail addresses: letizia.vainieri@aofoundation.org (M.L. Vainieri), a.lolli@erasmusmc.nl (A. Lolli), n.kops@erasmusmc.nl (N. Kops), domenicodatri88@gmail.com (D. D’Atri), david.eglin@aofoundation.org (D. Eglin), yayon@procore-bio.com (A. Yayon), mauro.alini@aofoundation.org (M. Alini),
}

sibylle.grad@aofoundation.org (S. Grad), k.sivasubramaniyan@erasmusmc.nl (K. Sivasubramaniyan), g.vanosch@erasmusmc.nl (G.J.V.M. van Osch). 
tissue engineering is reproduced. These tests can be used for pre-clinical testing of newly developed material designs in the field of scaffold engineering.

(c) 2019 Acta Materialia Inc. Published by Elsevier Ltd. All rights reserved.

\section{Introduction}

Articular cartilage is a load bearing tissue with a unique composition and structure. Once damaged, its poor intrinsic repair ability results in permanent functional impairment, which often leads to osteoarthritis in absence of treatment [1,2]. A number of studies have shown limited cell infiltration of the cartilage tissue as an impediment to endogenous repair [3]. Effective management of cartilage lesions can be challenging, creating a burden for both patients and clinicians. With conservative treatment being unsuccessful, surgical interventions are proposed for articular cartilage lesions, such as microfracture or osteochondral allograft transplantation. When perforations penetrating the subchondral bone are created in the context of marrow stimulating techniques (microfracture), invading cells often exhibit limit healing potential, producing a fibrocartilaginous tissue with poor mechanical properties, rather than hyaline cartilage [4]. To overcome this issue, cell delivery approaches like autologous chondrocyte implantation and matrix-induced autologous chondrocyte implantation ( $\mathrm{ACI}, \mathrm{MACI})$, have been established as cartilage repair methods [5-7]. Recently clinical interventions based on autologous mesenchymal stromal cells (MSCs) transplantation have been proposed [5-7]. When evaluating studies comparing patients treated with $\mathrm{ACI} / \mathrm{MACI}$ and with autologous bone marrow derived MSCs, similar improvements were reported in relation to clinical outcome and pain score $[8,9]$. Nonetheless these cell-based therapies face important limitations, due to enormous costs for the patients as well as cell handling, time and regulation related to safety [10].

The extracellular matrix (ECM) of articular cartilage is a highly functional dense connective tissue, but its restrictive barriers impede endogenous cell migration. Partial degradation of the ECM at the wound edge of the cartilage has been proposed to reduce its stiffness [11-13] and enhance endogenous cell migration. Although these findings have shown that cells, that are normally trapped in the dense ECM, are capable of initiating tissue repair once they reach the edge of the lesion, in term of diarthroidal joint studies have suggested that cells might normally come from bone and bone marrow side and even from synovium [14,15]. The induction of cell mobility to recruite cells into the defect is an attractive option that has already been described for in situ regeneration of multiple tissues $[14,16]$, in order to circumvent issues related to cell-based therapy. There is a pressing need to identify the optimal biomaterials [17] and recruitment factors that can be used as cell free approach for cartilage regeneration strategies. A variety of scaffolds and bioactive compounds were shown to promote stem and progenitor cell recruitment and improve cell differentiation $[3,18]$. However, to date, no studies have identified the effective biomaterial that would promote the recruitment and differentiation of endogenous stem/progenitor cells to achieve functional cartilage regeneration in situ.

Hyaluronan (HA) is a component of the cartilage matrix that has both chondro-protective and chondro-inductive properties [19]. HA-based biomaterials have been shown to enhance healing processes in osteochondral defects in rabbit and minipig models $[20,21]$. They possess a unique biochemical composition that recreate the embryonic-like microenvironment [22], which may be favorable for the regenerative process. HA-based hydrogels can be enzymatically cross-linked in situ, rendering the system safely injectable and non-invasive $[23,24]$. HA-Tyramine (HA-Tyr) hydrogels have been developed as drug carriers for protein delivery [25,26] and for tissue engineering applications [27]. It is known that by tuning the hydrogel the microenvironment can be modulated, which in turn can regulate spatial cell organization and matrix biosynthesis. HA-Tyr-conjugates have advantageous material chemistry perspectives, the system is enzymatically crosslinked via a reaction catalyzed by horseradish peroxidase (HRP) using hydrogen peroxide $\left(\mathrm{H}_{2} \mathrm{O}_{2}\right)$ as substrate. The fine tuning of its mechanical strength can be achieved by the $\mathrm{H}_{2} \mathrm{O}_{2}$ concentration without affecting the gelation rate [25]. It has been shown that varying the HA-Tyr hydrogel cross-linking density MSC differentiation and matrix biosynthesis can be modulated [28]. Fibrin-HA $(\mathrm{FB} / \mathrm{HA})$ combination is widely used in tissue engineering and the specific conjugation of $\mathrm{FB} / \mathrm{HA}$ hydrogel (Regenogel ${ }^{\mathrm{TM}}$ ), is well known for its applications in the regeneration of various tissues, such as cartilage and intervertebral disc $[16,23,29]$. The particular method employed for conjugation of HA to fibrinogen allows high versatility of the resulting hydrogels by alternating the molecular weight of HA, degree of activation and Fibrinogen/HA ratio. The resulting hydrogels are particularly stable compared to other Fibrin based scaffolds with remarkably lower rate of degradation of fibrin and a lager mesh size, thus allowing better cell migration and ECM deposition [23].

This study uses a sequence of assays to compare different HAcontaining hydrogels for cell mobility, differentiation and matrix deposition. We evaluated the ability of human bone marrow stromal cells (hBMSCs) to migrate in a hydrogel under the influence of different chemokines, i.e. PDGF-BB, RANTES and SDF-1 in a 3D spheroid-based assay. After selecting PDGF-BB as strongest stimulator of MSC migration, we tested the injectable $\mathrm{FB} / \mathrm{HA}$ formulation and HA-Tyr hydrogels with different cross-linking densities for their ability to allow cell migration and support chondrogenic differentiation in vitro. Finally, a bovine osteochondral explant model was used as hydrogel testing platform to monitor the recruitment of endogenous cells to the injury site in an in vivo mouse model.

\section{Materials and methods}

\subsection{Cell isolation and culture}

Bone marrow aspirates were collected from 6 patients undergoing total hip replacement (age 50-78 years) after informed consent (approved by the local Medical Ethical Committees of Erasmus MC: protocol MEC-2015-644; and Albert Schweizer Hospital: protocol 2011.07). Mesenchymal stem cells were isolated from leftover iliac crest bone chip material obtained from 1 patient (age 13 years) undergoing alveolar bone graft surgery (as leftover material with approval of local Medical Committee of Erasmus MC: MEC-2014-16). Human bone marrow stromal cells (hBMSCs) were expanded at a seeding density of 2300 cells $/ \mathrm{cm}^{2}$ in alphaMinimum Essential Medium ( $\alpha$-MEM; Gibco, Carlsbad, California, United States) supplemented with $10 \%$ fetal bovine serum (FBS, Gibco, Carlsbad, California, United States), $50 \mu \mathrm{g} / \mathrm{mL}$ gentamycin (Gibco, Carlsbad, California, United States), $1.5 \mu \mathrm{g} / \mathrm{mL}$ fungizone (Gibco, Carlsbad, California, United States), $1 \mathrm{ng} / \mathrm{mL}$ fibroblast growth factor 2 (FGF2; AbD Serotec, Puchheim, Germany) and $25 \mu \mathrm{g} / \mathrm{mL}$ ascorbic acid-2-phosphate (AA-2-P, Sigma-Aldrich, Saint Louis, MO). Medium was renewed twice a week. Passage 3 or 4 hBMSCs were used for in vitro experiments. 


\subsection{Synthesis of Fibrinogen-Ha and HA-Tyramine conjugates and} hydrogel formation

FB/HA conjugates were synthesized by the reaction of a buffered fibrinogen solution with a HA-active ester solution using HA molecular weight of $235 \mathrm{kDa}$ (LifeCore Biomedical, LLC, Chaska, $\mathrm{MN}, \mathrm{USA})$ at $\mathrm{FB} / \mathrm{HA} \mathrm{w} / \mathrm{v}$ ratio of $3.2: 1(6.25 \mathrm{mg} / \mathrm{mL}$ and $1.96 \mathrm{mg} / \mathrm{mL}$ respectively, (ProCore Ltd. Ness Ziona, Israel) [23]. For hydrogel formation, a thrombin solution (50 U/mL, Sigma-Aldrich, Missouri, USA) containing calcium chloride $\left(1 \mathrm{M} \mathrm{CaCl}_{2}\right)$ was mixed to $\mathrm{FB} / \mathrm{HA}$ conjugate, vortexed and polymerized at $37{ }^{\circ} \mathrm{C}$ for $30 \mathrm{~min}$. A similar formulation of $\mathrm{FB} / \mathrm{HA}$ hydrogel, containing higher molecular weight $\mathrm{HA}$, is approved for clinical use for the treatment of Osteoarthritis and associated pain (www.RegenoGel.com by ProCore Ltd, Israel).

HA-Tyramine was synthesized as previously described [30]. Briefly, sodium hyaluronate (280/290 kDa, Contipro Biotech S.R.O., Dolni Dobrouc, Czech Republic) was dissolved in deionized $\mathrm{H}_{2} \mathrm{O}$ $(1 \% \mathrm{w} / \mathrm{v})$. HA-Tyramine conjugates were prepared in a one-step reaction by adding $23.4 \mathrm{mmol}$ 4-(4,6-dimethoxy-1,3,5-triazin-2yl)-4-methylmorpholinium chloride (DMTMM, TCI Europe) as coupling agent and subsequently $25 \mathrm{mmol}$ tyramine hydrochloride (Tyr, Sigma Aldrich, Buchs, Switzerland) dropwise to the solution. After precipitation, lyophilization and reconstitution in PBS, UV-vis analyses were performed to confirm substitution of tyramine on HA $\left(\mathrm{DS}_{\mathrm{mol}} 14 \%\right)$. In a typical setup for hydrogel formation, freshly prepared solution of $0.5 \mathrm{U} / \mathrm{ml}$ HRP in phosphate buffered saline (PBS) was added to an aqueous solution of 3.5\% (w/v) of HATyr conjugates, and rotated overnight at $4{ }^{\circ} \mathrm{C}$. To induce hydrogel formation, different $\mathrm{H}_{2} \mathrm{O}_{2}$ concentrations $(150,300,600 \mu \mathrm{M})$ were added and immediately vortexed to form HA-Tyr hydrogels with different cross-linking densities (HA-Tyr 150, HA-Tyr 300 and HATyr 600, respectively), in order to provide a homogeneous distribution within the pre-hydrogel solution before gelation occurs. The concentrations of $\mathrm{H}_{2} \mathrm{O}_{2}$ were determined based on cross-linking density achievement and cell survival [28]. For the screening of factors to stimulate migration of MSCs, rat tail collagen I hydrogel (Life Technologies, Carlsbad, California, United States) was used. Briefly, $0.6 \%$ Collagen hydrogels were prepared on ice by mixing 10X PBS, $\mathrm{dH}_{2} \mathrm{O}$ and $1 \mathrm{~N}$ sodium hydroxide $(\mathrm{NaOH})$ and incubating at $37{ }^{\circ} \mathrm{C}, 5 \% \mathrm{CO}_{2}$, for $30-40$ min until a firm gel was formed, according to manufacturer's instructions.

\subsection{Rheological measurements}

For rheological study, all hydrogels $(400 \mu \mathrm{L})$ were prepared in 12 well plates. Oscillatory tests (amplitude and time sweep) were performed at $37^{\circ} \mathrm{C}$ using an Anton-Paar MCR-302 rheometer equipped with a Peltier controller and $25 \mathrm{~mm}$ plate-plate geometry. To monitor shear elastic moduli (G') and loss of moduli (G") of the hydrogels a humid chamber was created by placing water drops around the platform and a chamber cover on top. The storage modulus ( $\left.G^{\prime}\right)$ was measured at a strain of $1 \%$, which was determined to be within the linear viscoelastic region.

\subsection{Swelling ratio studies and mesh size calculation}

Hydrogel disks $(200 \mu \mathrm{L})$ were swollen in PBS for $72 \mathrm{~h}$ at $37{ }^{\circ} \mathrm{C}$. Then the hydrogel were gently blotted dry with Kimwipe and weighed immediately after. The disks were lyophilized overnight to obtain the dry weight. The swelling ratio was calculated by the following equation:

Swelling ratio $=\mathrm{Ws} / \mathrm{Wd}$ where Ws is the swollen weight and Wd is the dry weight.

The mesh size of HA-Tyr 150, 300 and 600 was calculated based on equilibrium swelling theory, using Flory-Rehner model [31,32].

\subsection{In vitro $3 D$ spheroid-based migration assay}

3D spheroid migration assay was used to evaluate cell migration as a function of different chemoattractants and varying concentrations of hydrogel. Micro-molds (Micro Tissues 3D Petri Dish, Sigma Aldrich, Missouri, USA) were used to cast 3D agarose Petri Dish, in order to form uniform size spheroids (Fig. 1A). Each micromold forms 256 circular micro-wells (diam. $400 \mu \mathrm{m}$ x $800 \mu \mathrm{m}$ ) in a $16 \times 16$ array. After gelation, the agarose micro molds were placed in a 12 well-plate and equilibrated with $\alpha$-MEM supplemented with $10 \% \mathrm{FBS}, 25 \mu \mathrm{g} / \mathrm{ml} \mathrm{AA}-2 \mathrm{P}$ at $37^{\circ} \mathrm{C}, 5 \% \mathrm{CO}_{2}$ for $1 \mathrm{~h}$. In parallel, hBMSCs $\left(1 \times 10^{6} \mathrm{cell} / \mathrm{ml}\right)$ were fluorescently labelled according to the manufacturer's instructions (Vybrant CFDA-SE Cell tracer Kit, Thermo Fisher, Carlsbad, California, United States). Suspensions of CFDA-SE labelled hBMSCs $\left(1.28 \times 10^{5}\right.$ cells $)$ were seeded into each agarose micro-mold and incubated at $37{ }^{\circ} \mathrm{C}, 5 \% \mathrm{CO}_{2}$ for $24 \mathrm{~h}$ in culture media, in order to form spheroids containing 500 cells per micro-well. The next day, spheroids formation was assessed using a standard inverted microscope to exclude the 3D Petri dishes containing uneven size spheroids or the presence of individual cells. To collect spheroids, the micro molds were inverted in a new 12 well-plate containing $\alpha$-MEM supplemented with $1 \%$ insulin, transferrin and selenium (ITS+, Sigma Aldrich, Missouri, United States), $25 \mu \mathrm{g} / \mathrm{mL}$ AA-2P (called from now on serum free medium, SF) and centrifuged for $5 \mathrm{~min}$ at $120 \mathrm{~g}$. The SF medium containing the harvested spheroids was transferred in falcon tube and centrifuged for $30 \mathrm{~s}$ at $300 \mathrm{~g}$ to remove the supernatant. Then spheroids seeding was done after partial gelation on collagen gel (as it gels slowly), in order to avoid spheroids settling to the bottom of the gel and consequently fusion. Chambers slides (Nunc cell culture imaging 8 wells; Thermo Fisher, Carlsbad, California, United States) were used to polymerize collagen gel, $125 \mu$ l were added to each well $(9.4 \mathrm{~mm}$ and $10.7 \mathrm{~mm}$ in size with a thickness of $1.2 \mathrm{~mm}$ ).

In FB/HA and HA-Tyr hydrogels (HA-Tyr 150, 300 and 600), the spheroids were uniformly resuspended in the hydrogel prior gelation. As these hydrogels polymerize rapidly, there was no problem of spheroid settling or fusion. $1 \mathrm{~mL}$ containing 240 spheroids was transferred into each well of 12 well-plate (diameter of $22.8 \mathrm{~mm}$ and height of $2.4 \mathrm{~mm}$ ) and incubated for gelation at $37^{\circ} \mathrm{C}$ respectively for $30 \mathrm{~min}$.

Collagen I hydrogels containing about 30 spheroids were cultured for $48 \mathrm{~h}$ in SF medium in the presence or absence of 50 or $100 \mathrm{ng} / \mathrm{mL}$ of chemokine (C-C motif) ligand 5 (CCL5/RANTES), stromal derived factor 1 (SDF-1) or platelet derived growth factor $B B$ (PDGF-BB, Peprotech, NJ, USA); whereas HA-based hydrogels were cultured with or without addition of $50 \mathrm{ng} / \mathrm{mL}$ PDGF-BB for $24 \mathrm{~h}$, $48 \mathrm{~h}$ and $72 \mathrm{~h}$ [33]. For FB/HA hydrogels, Aprotinin $(500 \mathrm{kIU} / \mathrm{ml}$, Sigma Aldrich, Missouri, USA) was supplemented into the media to prevent early degradation during culture. To monitor cell migration, a confocal microscope was used (Leica SP5, 10X magnification, FITC channel). Through the z-stack option of the confocal microscope all the spheroids were imaged from the top to the bottom in order to consider every single cell path, enabling individual cells tracking (3D reconstruction, Suppl. Fig.1A). Cell migration area from the core was quantified by averaging automated counts from 5 random spheroids, running a macro developed in house using Fiji image processing software. The macro developed in house measures the cell migratory area in $2 \mathrm{D}$, by running the $\mathrm{Z}$ Project function the software projects at maximum intensity all the stacks acquired covering the whole 3D area (Suppl. Fig 1B). From these pictures the macro excludes the core and sprouting cells (red) and count the area of cell migrating from the core (green), making concentric circles of $10 \mu \mathrm{m}$ radius (yellow). The algorithm generated concentric circles, each of increasing $10 \mu \mathrm{m}$ radius and tracked the cells present in each of these circles. Then the area of migrating cells and distance of cells in each of these circles, with respect to 
A
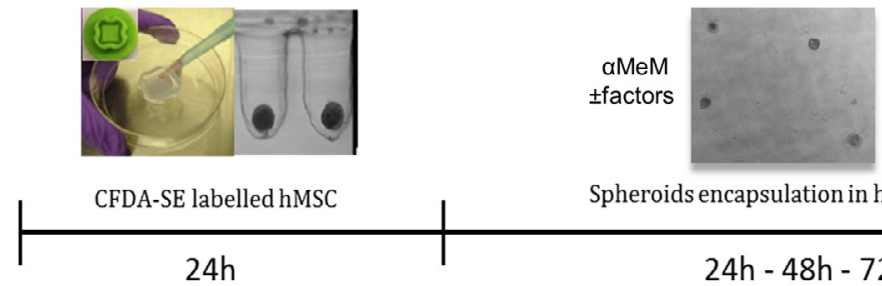

Spheroids encapsulation in hydrogels

$24 h-48 h-72 h$

spheroid formation

migration within the gel

B

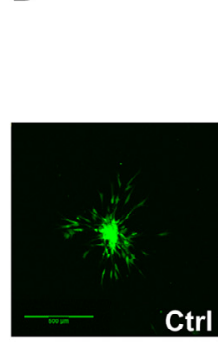

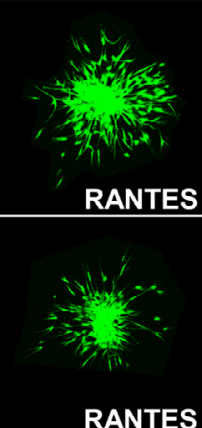

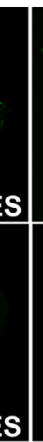

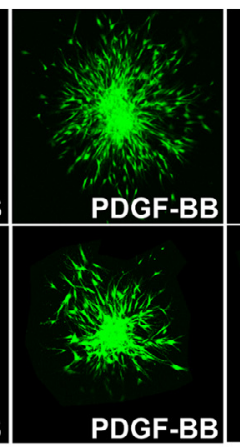

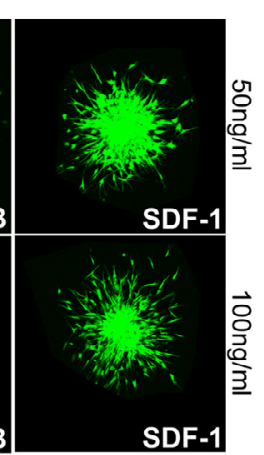

C

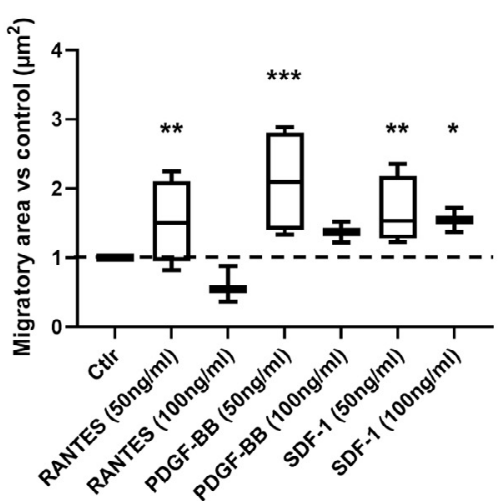

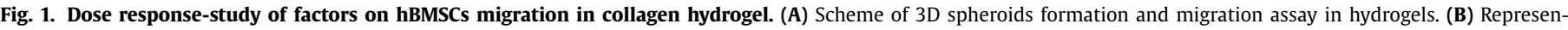

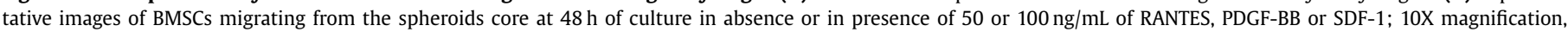

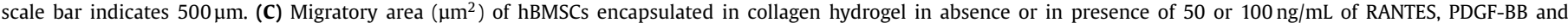
SDF-1. Results from 4 hBMSC donors assessed in triplicate (donor 2) and quadruplicate (donors 1,3 and 4 ) are shown; * $p<0.05, * * p<0.01$, ${ }^{* * *} p<0.001$.

the core, was calculated and the area of all migratory cells was summed up to get the total migratory area.

\subsection{HA-based hydrogels invasion assay}

To better mimic cell infiltration from the periphery into the gel, all HA-based hydrogels were formed in the presence or absence of $100 \mathrm{ng} / \mathrm{mL}$ PDGF-BB, this concentration was chosen based on our initial dose-response experiment and on a previous study [33]. $1 \mathrm{~mL}$ of hydrogel was polymerized into each well of 12 well-plate (diameter of $22.8 \mathrm{~mm}$ and height of $2.4 \mathrm{~mm}$ ), then the hydrogel was cut in an equal quarter of a circle. Each quarter of $250 \mu \mathrm{L}$ of HA-based hydrogel with a thickness of $2.4 \mathrm{~mm}$ was used for the invasion assay. Then the gels $(250 \mu \mathrm{L})$ were maintained in suspension in $50 \mathrm{~mL}$ falcon tubes for $3 \mathrm{~h}$ at $37^{\circ} \mathrm{C}$ in $500 \mu \mathrm{L}$ of SF medium containing CFDA-SE labelled hBMSCs $\left(5 \times 10^{5}\right.$ cells $)$ under gentle shaking to avoid cell settlement and to allow cell adhesion to the gels ( $n=3 /$ group). Afterwards $1.5 \mathrm{~mL}$ of fresh $\mathrm{SF}$ medium was added in each gel per tube and gels were cultured for 7 days at $37^{\circ} \mathrm{C}$ (Suppl. Fig. 2A). Medium was changed every second day. For cell ingrowth detection, all gels were imaged at confocal microscope. For HA-Tyr gels multiple z-stacks of $5 \mu \mathrm{m}$ intervals were acquired (10X magnification), whereas for $\mathrm{FB} / \mathrm{HA}$ hydrogels due to the opacity, tile scans were performed in the center after cutting the hydrogel in the middle; cell infiltration was visualized in the FITC channel.

\subsection{PDGF-BB release from hydrogels}

The release of PDGF-BB from HA-based hydrogels in vitro was assessed as previously described [34]. The selected dose of PDGFBB used in this assay was similar to in vivo experiment (see paragraph 2.10). Briefly, $300 \mu \mathrm{L}$ of hydrogels (diameter of $10.7 \mathrm{~mm}$ and thickness of $3.4 \mathrm{~mm}$ ) loaded with $2 \mathrm{ng} / \mu \mathrm{L}$ PDGF-BB, were formed in 48 well-plates at $37^{\circ} \mathrm{C}$. Then $600 \mu \mathrm{L}$ of buffer (PBS, $0.5 \%$ BSA) was added to the plate and incubated at $37^{\circ} \mathrm{C}$ for 7 days. At predetermined time points - 0, $2 \mathrm{~h}, 8 \mathrm{~h}, 24 \mathrm{~h}, 72 \mathrm{~h}, 120 \mathrm{~h}, 168 \mathrm{~h}-$ half of the medium $(300 \mu \mathrm{L})$ was collected and replaced by the same volume of fresh medium. Cumulative release of PDGF-BB was measured by quantifying the chemokine in the medium using an ELISA kit (human PDGF-BB, DuoSet ELISA, R\&D System, Minnesota, USA).

\section{8. hBMSCs encapsulation and chondrogenic differentiation in HA-based hydrogels}

Briefly, hBMSC-FB/HA and hBMSC-HA-Tyr suspensions were mixed with thrombin solution and with $0.5 \mathrm{U} / \mathrm{mL}$ HRP and varying concentrations of $\mathrm{H}_{2} \mathrm{O}_{2}(150,300,600 \mu \mathrm{M})$ respectively, to form cell-hydrogels constructs with a cell density of $3 \times 10^{6}$ cells $/ \mathrm{mL}$ in 12 well-plates. After gelation for $30 \mathrm{~min}$, the constructs were cultured in complete chondrogenic medium (CCM) for four weeks (day 0 was used as control); medium was changed every second day. The CCM consisted in Dulbecco's modified Eagle's medium with Glutamax (DMEM-HG; Gibco, Carlsbad, California, United States) supplemented with $1 \%$ ITS, $50 \mu \mathrm{g} / \mathrm{mL}$ fungizone, $1.5 \mu \mathrm{g} / \mathrm{mL}$ gentamicyn, $1 \mathrm{mM}$ sodium pyruvate (Gibco, Carlsbad, California, United States), $40 \mu \mathrm{g} / \mathrm{mL}$ proline (Sigma Aldrich, Missouri, USA), $100 \mathrm{nM}$ Dexamethasone (Sigma Aldrich, Missouri, USA), $10 \mathrm{ng} / \mathrm{mL}$ recombinant human transforming growth factor beta 1 (TGF- $\beta 1$; R\&D System, Minnesota, USA). The hBMSC used in this assay were isolated from patients undergoing total hip replacement and from the iliac crest chip of 1 patient. Samples were collected for RNA isolation or histological analysis on day 28.

\section{9. $R N A$ isolation and $q R T-P C R$}

After 28 days of culture, hBMSC/HA-Fibrin and hBMSC/HATyr-constructs were manually homogenized using a pellet pestle, further digested with hyaluronidase, and total RNA was extracted 
A

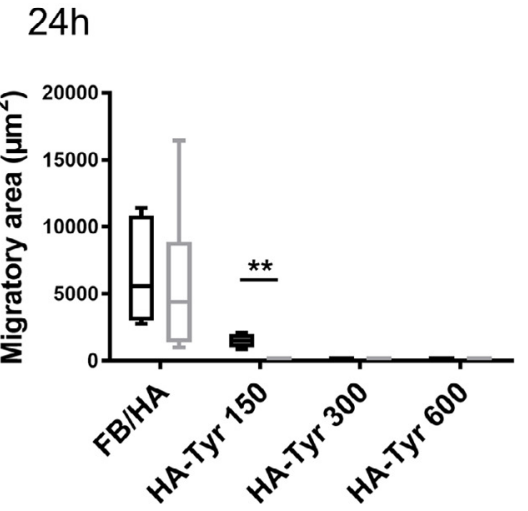

B
$48 h$

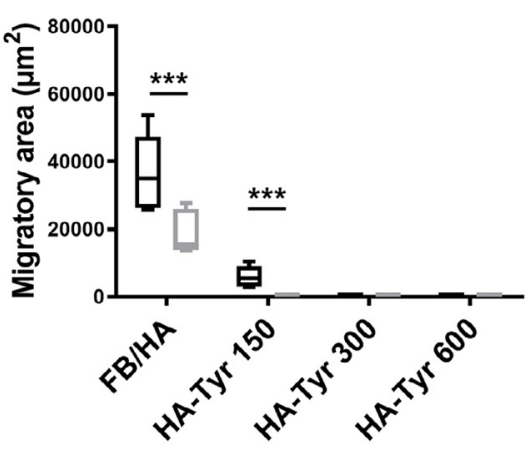

$72 \mathrm{~h}$

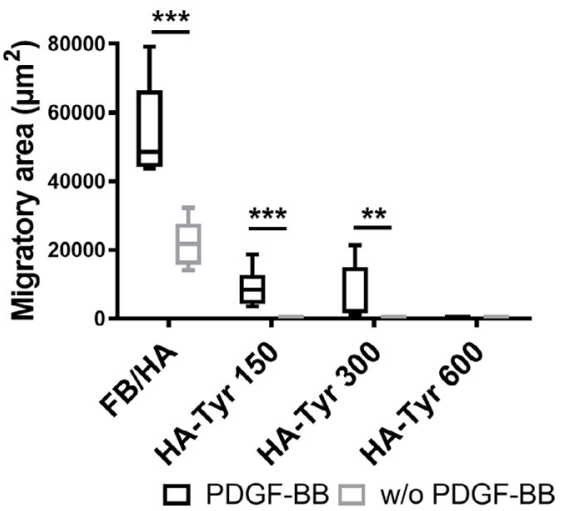

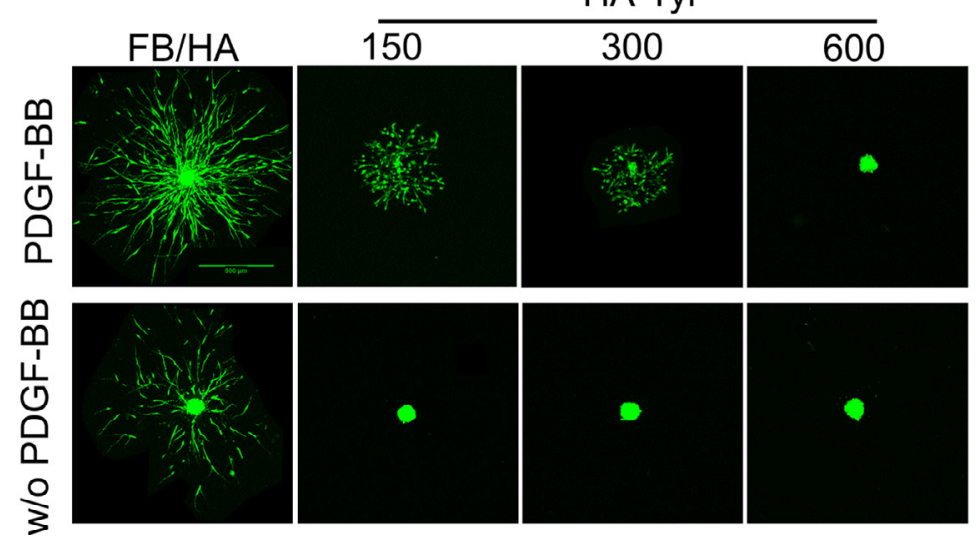

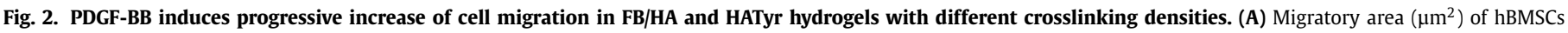

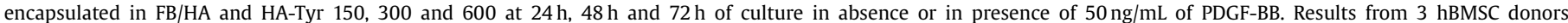

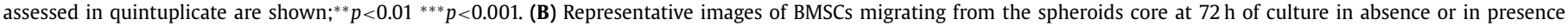
of 50 and $100 \mathrm{ng} / \mathrm{mL}$ of PDGF-BB; 10X magnification, scale bar indicates $500 \mu \mathrm{m}$.

using the miRNeasy micro Kit (Qiagen, Hilden, Germany), according to the manufacturer's instructions. RNA concentration and quality were measured using NanoDrop ND100 UV-VIS spectrophotometer (Isogen Life Science B.V, de Meern, the Netherlands). cDNA was prepared using RevertAid First Strand cDNA Synthesis Kit (ThermoFisher, Carlsbad, California, United States) according to the manufacturer's instructions. qRT-PCR was performed in $20 \mu \mathrm{L}$ reactions on ABI Prism 7000 system (Applied Biosystem, Foster City, CA, USA) using either Taqman Universal PCR mastermix (Applied Biosystem, Foster City, CA, USA) or SyberGreen (Eurogenetc, Seraing, Belgium). The expression of collagen type 2 (COL2) and aggrecan (ACAN) was determined. Glyceraldehyde-3phosphate dehydrogenase (GAPDH) was selected as reference gene after comparison with other housekeeping genes [35]. Data were calculated as relative mRNA values.

\subsection{In-vivo subcutaneous osteochondral defect model}

To evaluate the effect of the hydrogels on cartilage repair via ingrowth of endogenous cells, an in vivo subcutaneous mouse model was used. All animal experiments were approved by the local animal committee (EMC3284, protocol number 116-14-02). Osteochondral defects were created in osteochondral biopsies $(8 \mathrm{~mm}$ diameter, $5 \mathrm{~mm}$ height) harvested from metacarpal-phalangeal joints of 3 to 8 months old calves as described previously [36]. Four $\mathrm{mm}$ diameter dermal biopsy punches (Stiefel Laboratories, Munich, Germany) and scalpels were used to create osteochondral defects. The defects in the osteochondral plugs were either left unfilled (empty) or filled with FB/HA or HA-Tyr 150 hydrogels with or without $1 \mu \mathrm{g} / \mathrm{mL}$ of PDGF-BB ( $n=5 /$ group). In comparison to in vitro migration and invasion assay, a higher concentration of PDGF-BB was employed since the growth factor in vivo is expected to be released over several days and more easily degraded by proteases [37]. Osteochondral explants were covered with NeuroPatch membrane (Braun, Melsungen, Germany) to prevent host cell ingrowth and were implanted subcutaneously in female NMRI $\mathrm{nu} /$ nu mice (Charles River, Wilmington, MA, USA) under isoflurane anaesthesia. Four incisions were made on the dorsum of each animal, and subcutaneous' pockets were created using a blunt blade; one construct was placed in every pocket and the incisions were closed with wound clips.

After 4 weeks, mice were euthanized by cervical dislocation, the constructs were carefully removed and fixed in $4 \%$ formalin for 5 days. Then samples were decalcified in 10\% EDTA for two weeks, subsequently embedded in paraffin and subjected to histology (Thionin staining) or immunohistochemistry (Collagen type 2 deposition).

\subsection{Histology and immunohistochemistry}

Retrieved samples were embedded in paraffin and sectioned ( $6 \mu \mathrm{m}$ sections). Slides were deparaffinised and stained with Thionin to visualize glycosaminoglycans in the extracellular matrix. Briefly, slides were first stained with Thionin solution $(0.04 \%$ Thionin in $0.01 \mathrm{M}$ aqueous sodium acetate, Sigma-Aldrich, Missouri, United States) for $8 \mathrm{~min}$ and differentiated in $70 \%$ ethanol for $8 \mathrm{~s}$. The cross-sectional area of the osteochondral defect, the number of the infiltrated cells and the area of newly formed 
Thionin positive tissue were determined using Fiji software (National Institutes of Health, Bethesda, MA, USA). Cell ingrowth into the hydrogels was assessed by counting the number of cell nuclei infiltrating the defect area of the cartilage layer $(\mathrm{CL})$ and the defect area of the subchondral bone (SB) in Thionin stained cross-sections ( $n=5$ /group, $n=3$ sections/sample). To convert RGB images in 8 bit we used a trainable weka segmentation plugin, in order to train the software to define the classes of area to exclude (different shadows of background, Thionin staining) and select the area of interest (in this case the cells nuclei). After extracting the results, we select the best threshold to extract the desired objects (cell nuclei). Cartilage formation was quantified as percentage of positive stained area, dividing the Thionin signal intensity in the defect (glycosaminoglycan deposition) by the defect area of the cartilage layer (CL) and the defect area of the subchondral bone (SB) as measured in full Thionin-stained cross-sections ( $n=5 /$ group, $n=3$ sections/sample). Fiji image processing software was used to identify areas using a protocol previously described [38].

For immunohistochemical analysis, deparaffinized sections from hydrogel samples were probed with mouse anti-human collagen type 2 antibody (II-II6B3, Developmental Studies Hybridoma Bank, Iowa City, IA, USA). Antigen retrieval was performed by incubation in $0.1 \%$ pronase (Sigma-Aldrich, Missouri, USA) in PBS for $30 \mathrm{~min}$ at $37^{\circ} \mathrm{C}$. Then slides were incubated with $1 \%$ hyaluronidase (SigmaAldrich) in PBS for $30 \mathrm{~min}$ at $37^{\circ} \mathrm{C}$ and subsequently with $10 \%$ goat serum (Sigma-Aldrich) to block non-specific binding. The primary antibody against collagen type 2 (1:100 dilution) or mouse IgG1 negative control (Serotech Ltd, Oxford, UK) in PBS containing $0.1 \%$ BSA was incubated overnight at $4{ }^{\circ} \mathrm{C}$ coupled with biotinylated $\mathrm{F}(\mathrm{ab}) 2$-labeled goat-anti mouse secondary antibody (\#115-066062; Jackson ImmunoResearch Europe) to prevent cross-reaction with mouse antigens. Excessive primary antibody was captured by addition of $0.1 \%$ normal mouse serum prior to the overnight incubation at $4{ }^{\circ} \mathrm{C}$ with the sections. The reaction was catalyzed by an alkaline-phosphatase-label conjugate (Label, HK-321-UK, Biogenex, CA, USA) diluted 1:100 in PBS/BSA and visualized by subsequent incubation of Neu Fuchsin substrate (Chroma, Kongen, Germany). Slides were counterstained with Haematoxylin.

\subsection{Statistical analysis}

The results were expressed as mean \pm standard deviation (SD). For the 3D spheroids-based migration assay in collagen gel, experiments were performed using 4 different hBMSC donors and triplicate per donor, a linear mixed model was used for migratory cell area data. Multiple comparisons were analysed with Sidak post hoc test. Conditions and donors were considered as fixed and random parameters, respectively. Normal distribution of the data or the residuals of the data were confirmed by both Kolmogorov-Smirnov and Shapiro-Wilk tests. In the 3D migration assay in HA-hydrogels, experiments were performed using 3 different donors and triplicate per donor, data were not normally distributed and KruskalWallis test was performed. For the quantification of cartilage repair in the osteochondral samples, experiments were performed using 5 explants per group and 3 sections per sample, statistically significant differences between untreated and hydrogel treated groups were determined by one-way ANOVA, Tukey test for multiple comparison. All tests were performed using SPSS software. Differences were considered statistically significant for $p<0.05$.

\section{Results}

\subsection{Effect of different chemotactic factors on hBMSC spheroids migration in hydrogel}

Although monolayer cell migration has commonly been used for migration studies, recent research shifted toward 3D culture as a more relevant biochemical and biomechanical microenvironment [39]. Here, we used a spheroid-based migration assay to examine the effect of chemotactic factors on the migration of hBMSCs. CDFA-SE fluorescently labelled hBMSC spheroids with an average diameter of $125 \mu \mathrm{m}$ were generated (Fig. 1A), placed on a collagen hydrogel and cultured in the absence or in the presence of 50 or $100 \mathrm{ng} / \mathrm{mL}$ PDGF-BB, RANTES or SDF- 1 . After $48 \mathrm{~h}$, cell migration was imaged (Fig. 1B). Exposure of SDF-1 (50 and $100 \mathrm{ng} / \mathrm{mL}$ ), PDGF-BB $(50 \mathrm{ng} / \mathrm{mL})$ or RANTES $(50 \mathrm{ng} / \mathrm{mL})$ increased hBMSC migration compared to control $\left({ }^{* *} p<0.001,{ }^{* *} p<0.01,{ }^{*} p<0.05\right)$, except for $100 \mathrm{ng} / \mathrm{mL}$ RANTES, although variability among donors was observed (Fig. 1C). These results demonstrate that $50 \mathrm{ng} / \mathrm{mL}$ of PDGF-BB was the most favourable of the tested factors based on higher tendency to increase among all tested donors.

\subsection{PDGF-BB promotes hBMSC migration in FB/HA and HA-Tyr hydrogels with different cross-linking densities in vitro}

In terms of physical impediment to 3D cell recruitment, the migration of CDFA-SE labelled hBMSCs was assessed in HA-Tyr hydrogels with different crosslinking densities (HA-Tyr 150, 300 and $600 \mu \mathrm{M} \mathrm{H}_{2} \mathrm{O}_{2}$ ) and $\mathrm{FB} / \mathrm{HA}$ hydrogels, with or without PDGF-BB exposure, using a $3 \mathrm{D}$ spheroid assay. Confocal imaging revealed that the area of cell migration from the spheroids in all HA hydrogels progressively increased over three days culture in the presence of $50 \mathrm{ng} / \mathrm{mL}$ PDGF-BB, except for the stiffer HA-Tyr hydrogels (HA-Tyr 600, Fig. 2A, B) that showed no migration at all. FB/HA hydrogels supported the widest cell migration area in presence of PDGF-BB (4-fold increase compared to FB/HA only hydrogels after $72 \mathrm{~h}$; Fig. 2A, B). In FB/HA gels the cells exhibited spindle-shaped morphology (Fig. 2B), which might have facilitated faster migration, whereas in HA-Tyr hydrogels (HA-Tyr 150, 300) cells showed populations of both spindle and rounded shaped morphology that might have reduced the migration ability. The migration in HA-Tyr hydrogels with different cross-linking density was found to be inversely correlated with the storage modulus of the hydrogel ( $G^{\prime}$; Suppl. Fig. 2).

Increased migration in the presence of PDGF-BB was observed at $24 \mathrm{~h}$ and $48 \mathrm{~h}$ for HA-Tyr hydrogels with lower crosslinking (HATyr 150), which were softer and fostered faster migration than stiffer gels (HA-Tyr 300,$600 ;{ }^{* *} p<0.01$ and ${ }^{* * *} p<0.001$ respectively; Fig. 2A). Based on the mesh size calculation described by Leach et al. [40], and assuming that HA-Tyr had the same density as HA, the mesh sizes were calculated to be $184.99 \pm 8.03$, $160.60 \pm 5.04$ and $130.85 \pm 7.04 \mathrm{~nm}$ for the HA-Tyr 150, 300 and 600 , respectively. At increased cross-linking density, the mesh size decreased according to a decreased swelling ratio (Suppl. Fig. 3A, B), resulting in a reduced migration kinetic.

To better mimic the process of hydrogel invasion by endogenous cells, CDFA-SE labelled hBMSCs in suspension were incubated with free-floating HA-based hydrogels, polymerized with or without $100 \mathrm{ng} / \mathrm{mL}$ of PDGF-BB, then cultured for 7 days (Suppl. Fig. 4A). Imaging of the hydrogels at day 7 suggested higher cell infiltration in $\mathrm{FB} / \mathrm{HA}$ hydrogel with PDGF-BB compared to $\mathrm{FB} / \mathrm{HA}$ only. In HA-Tyr hydrogels, cell migration looks to be higher in presence of the chemokine rather than without and dependent of crosslinking densities (Suppl. Fig. 4B).

\subsection{HA-based hydrogels support chondrogenesis in vitro}

With the aim to investigate whether FB/HA and HA-Tyr hydrogels are suitable for cartilage engineering purposes, their ability to support chondrogenic capacity of hBMSCs was evaluated. hBMSCloaded hydrogels were cultured for 28 days in CCM and gene expression at day 0 was used as control; hBMSC differentiation was further assessed by immunohistochemistry. At day 0 gene 
A

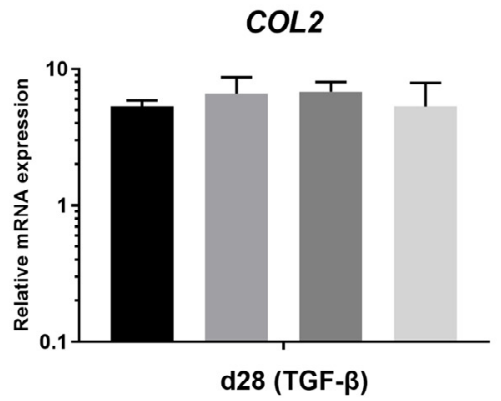

ACAN

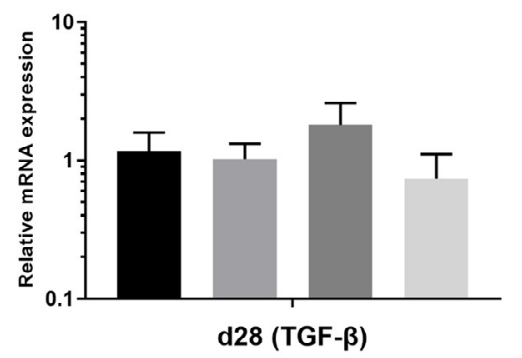

HA-Tyr 150

HA-Tyr 300

HA-Tyr 600

$\mathrm{FB} / \mathrm{HA}$

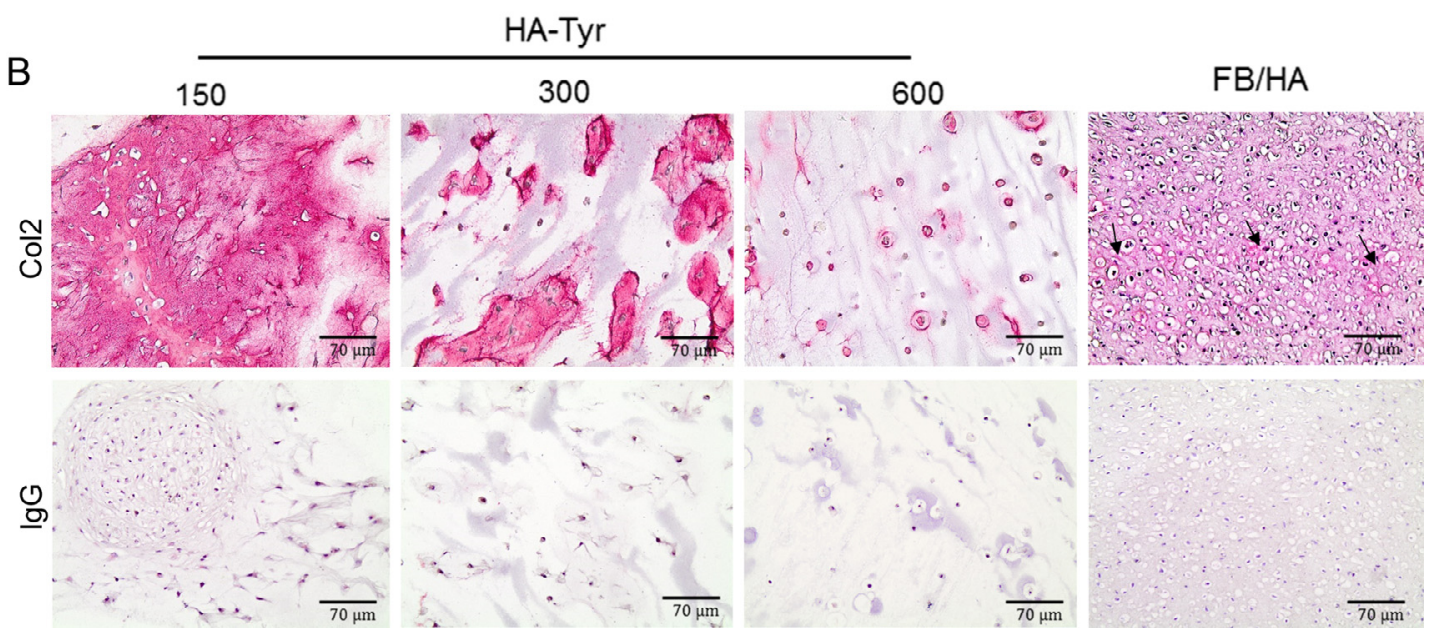

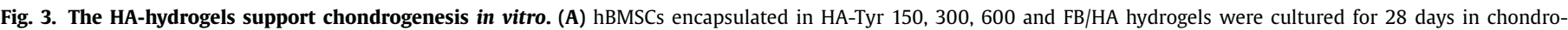

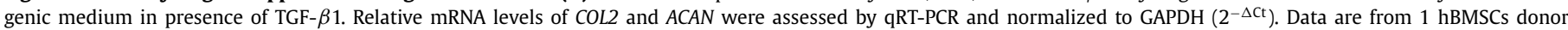

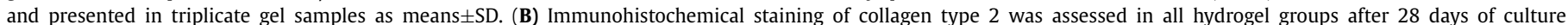

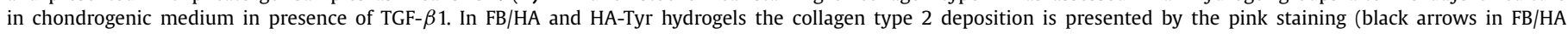

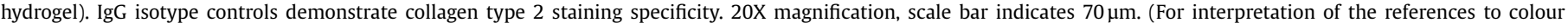
in this figure legend, the reader is referred to the web version of this article).

COL2A1 expression was undetectable and ACAN expression was very low with $\mathrm{Ct}$ values between 34 and 37 . The results indicate that hBMSC-FB/HA and hBMSC/HA-Tyr-constructs similarly allowed chondrogenic differentiation, as demonstrated by clear cartilage marker expression at day 28 (Fig. 3A). Immunohistochemical staining for collagen type 2 confirmed that $\mathrm{FB} / \mathrm{HA}$ constructs exhibited areas of newly synthesized matrix and cells with a chondrocytelike morphology (i.e. rounded and residing within lacunae Fig. 3B). Interestingly, collagen type 2 deposition in HA-Tyr hydrogels was limited to the pericellular space except for HA-Tyr 150 where the staining was diffuse in the matrix (Fig. 3B), indicating an inverse relationship between the cross-linking density and the extent of neocartilage tissue deposition. Since improved cell migration and cartilage matrix formation were observed in HA-Tyr hydrogels with the lowest cross-linking density, HA-Tyr 150 and FB/HA hydrogels were selected for further in vivo experiments.

\section{4. $\mathrm{FB} / \mathrm{HA}$ hydrogels improve endogenous cartilage tissue repair in an in vivo subcutaneous model}

To evaluate the ability of the selected hydrogels to support endogenous cartilage repair in vivo, osteochondral explants with simulated defects were filled with FB/HA and HA-Tyr, both loaded or not with PDGF-BB, and implanted subcutaneously in nude mice (Fig. 4A). After 4 weeks, osteochondral explants were collected and analyzed by histology. Data revealed differences between the groups in number of cells colonizing the defect through full-depth cartilage and subchondral bone (Fig. 4B, C, Suppl Fig. 5). While cells were evenly distributed throughout the whole area of $\mathrm{FB} / \mathrm{HA}$ gels (both cartilage and subchondral zone), cell ingrowth was lim- ited to the periphery in the vast majority of the HA-Tyr gels (Fig 4B). Cell infiltration was significantly higher in the cartilage layer and subchondral bone of FB/HA gel group without PDGFBB compared to HA-Tyr group without PDGF-BB $\left({ }^{*} p<0.05\right.$ and ${ }^{* * *} p<0.001$ : Fig. 4 C). Scarce cell infiltration was noticed in only 2 out of 5 samples in the empty defect group (data not shown). When FB/HA and HA-Tyr hydrogels were loaded with PDGF-BB, no significant differences in endogenous cell ingrowth were observed in comparison to untreated hydrogels (Fig. 4C), despite approximately $35 \%$ of PDGF-BB was released in $\mathrm{FB} / \mathrm{HA}$ after one week in vitro (Suppl. Fig. 6). This suggests that the factor release did not exert any appreciable effect on migration in the hydrogels (Fig. 4B, C).

In addition to higher cell infiltration in $\mathrm{FB} / \mathrm{HA}$ gels, cell mediated matrix production was significantly enhanced in the cartilage areas of untreated $\mathrm{FB} / \mathrm{HA}$ gels in comparison to HA-Tyr gels $\left({ }^{*} p<0.05\right.$, Fig $\left.4 \mathrm{~B}, \mathrm{D}\right)$. The subchondral bone areas showed similar GAG production and no statistical differences were observed. Interestingly, the addition of PDGF-BB to FB/HA gels inhibited cartilage formation $\left({ }^{* *} p<0.01\right.$, Fig. $\left.4 \mathrm{~B}, \mathrm{D}\right)$, while in HA-Tyr gels no significant differences were observed when PDGF-BB was added (Fig. 4B, D). Finally, deposition of collagen type 2 in vivo confirmed a similar pattern to GAG deposition (Fig. 4E).

\section{Discussion}

In this study we compared different types of HA-containing hydrogels for their capacity to support cell migration and chondrogenesis of hBMSC in vitro, and to promote recruitment of endogenous cells to the wound site, followed by cartilage repair 
A
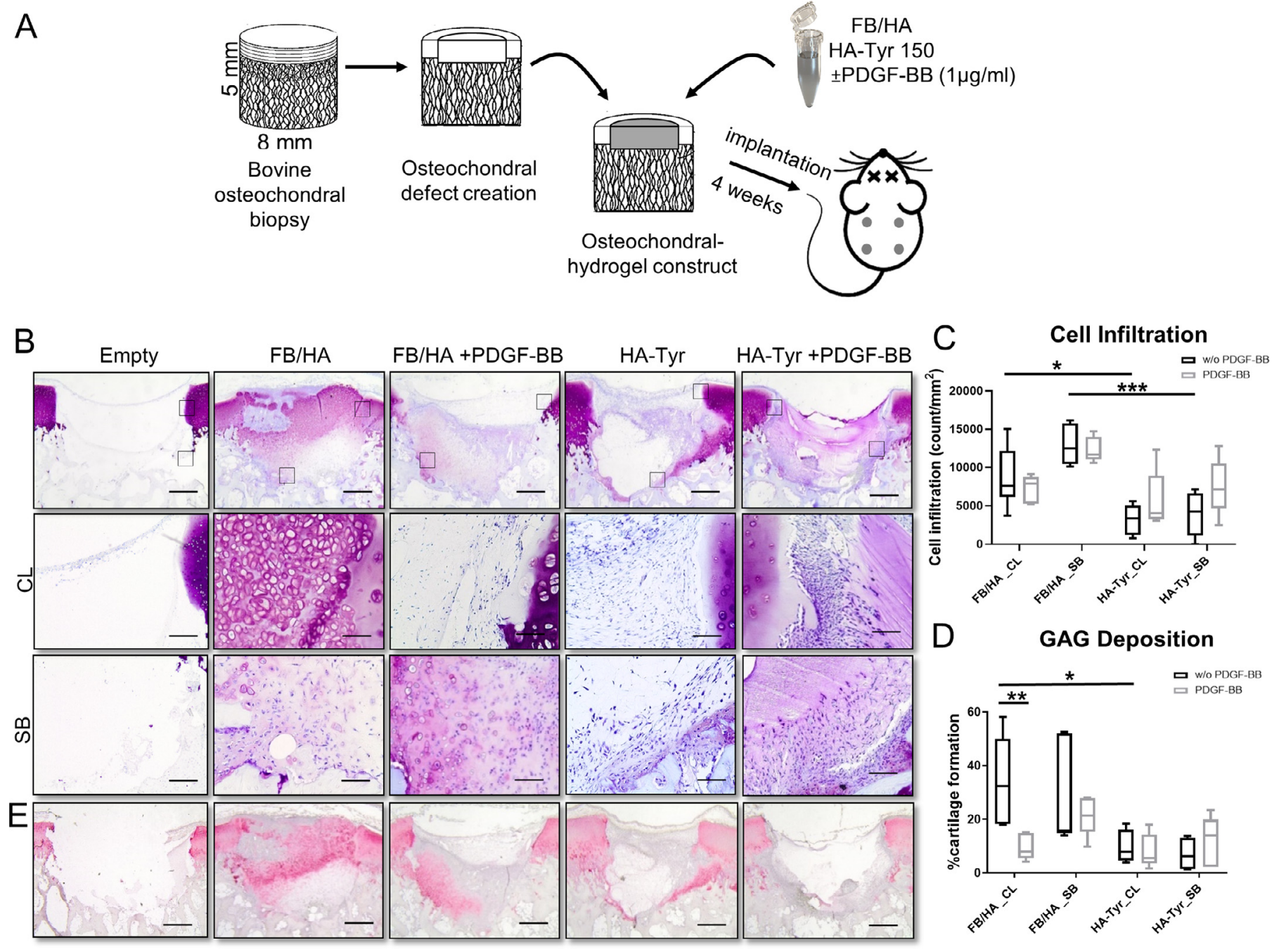

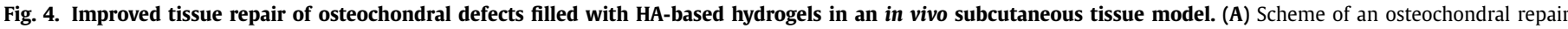

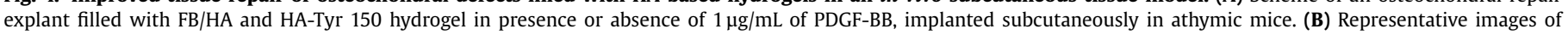

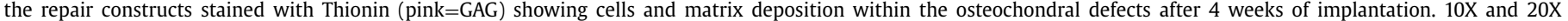

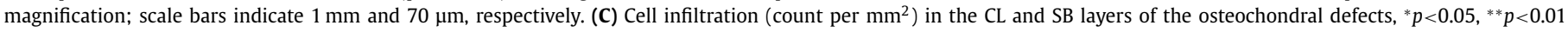

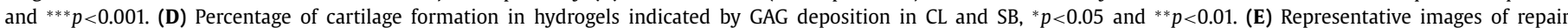

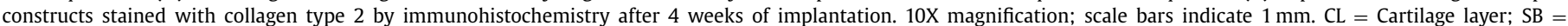
Subchondral bone.

in an osteochondral defect model in vivo. We showed that the FB/HA conjugated formulation enhanced a spontaneous cellular healing response and was more supportive for cartilage repair compared to the HA-Tyr hydrogel. In addition, the provision of PDGF-BB, chosen as the most favorable chemotactic agent, did not increase cell infiltration into the tested hydrogels but impaired chondrogenesis in vivo.

Our approach is based on the use of an advanced platform employed as a pre-clinical tool to screen new biomaterials and biomolecules for their potential to support endogenous cartilage repair. The advantage of this strategy is the application of more relevant experimental models due to the use of an in vitro 3D spheroids-based migration assay and an osteochondral defect model, which bring our approach a step closer to physiologically relevant systems. This could be widely applied to achieve stronger experimental evidence of the not well-characterized dynamic process of cell homing and to uncover the delicate step of early cell migration into biomaterials.

The ideal hydrogel should allow cell adhesion, migration and differentiation to favor the synthesis of extracellular matrix components necessary to mimic the native properties of cartilage.
However, tuning the gels to match not only cartilage composition and architecture but also mechanical properties to sustain the load, may prevent cell ingrowth that is necessary for the first steps of endogenous tissue repair. Consistent with other in vitro studies [28], we found that changes in mechanical properties influenced cell spreading, migration and differentiation. The modulation of HA-Tyr cross-linking degrees (150, 300 and $600 \mu \mathrm{M} \mathrm{H}_{2} \mathrm{O}_{2}$ ), while keeping HA-Tyr and HRP concentrations constant, was the major determinant for both cell migration and matrix synthesis during hBMSC chondrogenesis.

The resulting hydrogels ranged in storage modulus from 80 to $3000 \mathrm{~Pa}$, which mimics the mechanical properties of certain native cartilaginous tissues like the nucleus pulposus of the intervertebral disk (3-8 kPa; [41]), but is lower than the value reported for bovine adult cartilage (range $300-800 \mathrm{kPa},[42]$ ). However, cell migration was inhibited in HA-Tyr 600 hydrogels, indicating cell spreading limitations in stiffer highly crosslinked materials [43]. These stiffer gels, however, also have lower mesh size. In general, migration was strongly dependent on crosslinking, indeed gels with low crosslink density have both lower stiffness and higher mesh size (HA-Tyr $150)$, and foster faster migration; albeit the migration was always 
less in HA-Tyr than in FB/HA gels. Despite the similar stiffness ( $G^{\prime}$ ) of $\mathrm{FB} / \mathrm{HA}$ and HA-Tyr 150 , cell migration was profoundly affected by the different HA concentration as well as by the different network and the presence of components that improve cell adherence.

To ameliorate cell migration on HA-Tyr hydrogels further cues could be implemented, such as the Arg-Gly-Asp (RGD) binding sequences to improve the integrin-mediated cell attachment [44].

Chondrogenesis occurred in all tested hydrogels, as indicated by comparable gene expression levels of COL2 and ACAN. While FB/HA, HA-Tyr 150 and 300 hydrogels showed collagen type 2-rich matrix production, HA-Tyr 600 microenvironments showed only pericellular collagen type 2 deposition. Previous works [28] demonstrated extensive collagen type 2 deposition in the newly formed HA-Tyr matrix. Although G' values of our gels were much lower ( 0.08 and $0.45 \mathrm{kPa}$ in HA-Tyr 150 and 300 , respectively), this suggests that mechanical stiffness is not the only factor that influences stem cell fate [45]. It is possible that the higher amount of HA-Tyr used to form the hydrogel ( $3.5 \% \mathrm{w} / \mathrm{v}$ vs $2 \% \mathrm{w} / \mathrm{v})$ increased its density, which has been shown to negatively affect matrix deposition by hBMSCs [46]. Furthermore, the higher concentration may have increased its viscosity, which in turn may have hindered the diffusion of nutrients and growth factors in all the HA-Tyr constructs, which is known to influence the effectiveness of hBMSC chondrogenesis [47], thereby decreasing GAG deposition. The combination of those factors may have decreased the ability of those hydrogels to allow migration and support matrix accumulation. To further support our observations, a recent study has shown that increased HA crosslinking density resulted in an overall more restricted matrix distribution, while detecting no statistically significant differences in collagen type 2 expression among all the groups [48].

Consistently with other reports [37,49], we found that PDGF-BB was the most effective chemoattractant of hBMSCs in hydrogels, among the factors tested. PDGF-BB is a well-known mitogen and we cannot thus completely rule out a contribution of cell proliferation in the 3D spheroid in vitro assay. Nevertheless, cells that detached from the core were identified as migrating cells and proliferation, which would have increased the size of the core, did not influence this measurement. It should also be considered that both processes are desirable and necessary in a context of endogenous tissue repair in vivo, in order to guarantee proper cell colonization of the site of injury.

It is worth noting that the PDGF-BB gradient enhanced shortterm spheroid migration in vitro (3 days) and improved cell infiltration of hydrogels at 7 days of culture in HA-based hydrogels. Our release study of PDGF-BB over 7 days suggested that a chemotaxis gradient might have been less pronounced within HA-Tyr hydrogels than with FB/HA gels. Earlier studies exploring the influence of mechanical strength of HA-Tyr hydrogels on protein release demonstrated that release profile of the molecules depended on mesh size, with the release rate decreasing with decrease in mesh size [25]. The higher concentration of HA within HA-Tyr compared to FB/HAhydrogels, however, might also have increased the electrostatic interactions among their hydrophilic groups and the charged amino acid residues of the PDGF-BB [50], impeding a sustained delivery.

Although 3D migration studies can provide valuable informations, the majority of conventional in vitro hydrogel culture systems do not recapitulate the native tissue properties [51]. Furthermore, a recent study demonstrated that the in vitro microenvironment is not exhaustive to study the applicability of biomaterials for cartilage repair [52]. Therefore, a fundamental prerequisite is the testing of 3D cell migration and differentiation in a more relevant osteochondral-like system, in order to closely mimic a joint-like microenvironment. To validate our in vitro findings, FB/HA and HA-Tyr 150 hydrogels, with or without PDGF-BB, were placed in osteochondral defects in an explant model and implanted subcutaneously in vivo. Cellular invasion was evident by 4 weeks in both hydrogels, though infiltration was most advanced in the $\mathrm{FB} / \mathrm{HA}$ hydrogels, which allowed a uniform distribution of cells. Interestingly, the bridging tissue in the untreated $\mathrm{FB} / \mathrm{HA}$ constructs, closing over $85-90 \%$ of the osteochondral gap compared to HA-Tyr hydrogels, resulted also in an increased cartilage matrix formation $\left({ }^{*} p<0.05\right.$ and $\left.{ }^{* *} p<0.01\right)$, and subsequently more collagen type 2. A possible explanation for the extensive differences in cell infiltration between the FB/HA and HA-Tyr hydrogels might be that the high fibrin content (FB/HA 3.2:1) favoured binding of cells to its $3 \mathrm{D}$ architecture, and accelerated cell migration in the porous clots containing hyaluronan [53]. The HA in the FB/HA hydrogels may have influenced the behavior and function of cells involved in the remodeling of the damaged tissue [54]. Whereas the high content of low molecular weight HA $(280 \mathrm{kDa})$ in the HA-Tyr gels may have acted as a barrier to cell adhesion and migration [55], therefore slowing this process. We also noticed that 2 out of 5 osteochondral empty defects, implanted as controls, were partially colonized by cells. Despite the presence of a membrane patch, it is possible that liquid or blood after surgery reached the osteochondral defects. Indeed, part of the infiltrated cells were red blood cells. Furthermore, as the bovine explants were harvested from calves aged 6-8 months, the young and healthy material is likely to provide a favorable environment for repair.

This study showed a reduction in the size of cartilage lesion and enhanced regeneration of the cartilage using FB/HA hydrogels without exposure to growth factor before implantation. Interestingly, addition of PDGF-BB worsened the repair of cartilage. A previous study on osteochondral repair in a rat model, demonstrated no significant presence of cartilage matrix deposition when the defect was filled only with PDGF-BB loaded in heparin-conjugated fibrin gels [37]. Although this study used higher concentrations of PDGF-BB $(8.5 \mu \mathrm{g} / \mathrm{mL}$ and $17 \mu \mathrm{g} / \mathrm{mL})$ compared to the present study $(1 \mu \mathrm{g} / \mathrm{mL})$, these findings are in line with our observations, suggesting that the presence of PDGF-BB, although not influencing cell recruitment, diminished chondrogenic differentiation leading to more fibrous tissue formation. Future studies will be performed to evaluate a dose-dependent effect of PDGF-BB on cartilage repair after in vivo transplantation and explore the efficacy of other chemotactic agents [16]. To further improve the quantity or quality of the matrix produced by the recruited cells, our system can be functionalized, for example by adding pro-chondrogenic factors [56,57], that can stimulate cartilage formation or inhibit hypertrophy.

Our findings with the osteochondral explant model are partially in line with clinical outcomes of the microfracture procedure $[4,58]$ : cells are recruited without supplementation of exogenous factors and spontaneously generate a cartilaginous tissue, albeit this is a mixed hyaline/fibrous tissue with non-favorable long term outcome. Although the origin of these reparative cells needs further analysis, we suppose that the migrating cells are either endogenous stem/progenitor cells from the subchondral bone region, either perivascular or bone lining cells, that have differentiated towards the chondrocyte lineage, since the newly generated tissue was GAG and collagen type 2 positive. It is clear that the construct is revascularized upon implantation, meaning a connection is made with the mouse system [59]. Hence, we cannot exclude the presence of cells from murine origin in our plugs. Further investigations of the origin of these cells would be interesting, although this poses significant challenges in discriminating mouse and bovine cells in decalcified sections.

Subcutaneous implantation does not entirely recapitulate the diarthroidal joint in terms of cellular components, immunologic response and mechanical stimuli, it allows only short-term evaluation of cell colonization and matrix production in vivo. To study the effect of mechanical stimuli to our endogenous cartilage repair 
system, the use of a bioreactor system to simulate physiological joint kinematics in vitro can be useful [60]. Multiaxial loading was shown to induce production and activation of transforming growth factor-beta (TGF- $\beta 1$ ), thereby promoting chondrogenesis of BMSCs [61]. Since the process of endogenous cartilage repair and the involved cell populations are still not well characterized, this system can be implemented to carry out additional studies including preclinical screening of targeted therapies and biomaterial-based implants. Eventually, the long-term therapeutic effects will need to be validated in large animal models of osteochondral injury.

\section{Conclusion}

The manuscript emphasizes the application of an advanced biomaterial testing platform to select the most promising hydrogel to support cell migration and differentiation for cartilage regeneration, posing interesting features in the use of $\mathrm{FB} / \mathrm{HA}$ conjugated hydrogel, even in the absence of the factor stimulating migration. Of note, both in vitro and vivo findings indicate that in the $\mathrm{FB} / \mathrm{HA}$ hydrogel the use of stimulating factors was not necessary to create a local ECM microenvironment amenable for endogenous cell recruitment in both cartilage and bone layers. Particular consideration should be given on creating an environment where cues may be introduced to stimulate matrix deposition and improve the quality of the newly-formed cartilage, e.g. by silencing antichondrogenic factors [62], and promote proper collagen fiber alignment [63]. Combination of these processes will lead to an ideal situation where different but complementary regulators create an optimal microenvironment for cartilage repair.

\section{Declaration of Competing Interest}

Vainieri M.L., Lolli A., Kops N., Eglin D, Alini M., Grad S., Sivasubramaniyan K., van Osch G.J.V.M., declare they have no conflict of interest. Yayon A. is an employee of Procore Ltd.

\section{Acknowledgment}

We thank Eric Farrell and the department of oral and maxillofacial surgery at Erasmus MC for providing paediatric MSCs, Mariana Leandro Cruz from the Dept. of Orthopaedics, Erasmus MC for her help with performing the migration assays, Gert-Jan Kremers from Erasmus MC Optical imaging centre for his help with analyzing the migration, Flavio Linardi from AO Research Institute for producing HA-Tyramine hydrogel and Eilat Bain from Procore for supplying of the FB/HA hydrogel.

\section{Funding source}

This project has received funding from the European Union's Horizon 2020 research and innovation programme under Marie Sklodowska-Curie Grant Agreement No. 642414, SmartStep a collaborative grant of the Dutch Arthritis Foundation (CO-14-1-002) and the Medical Research Council UK (MRC-MR-L022893), and a grant from NWO (Perspectief grant P15-23).

\section{Supplementary materials}

Supplementary material associated with this article can be found, in the online version, at doi:10.1016/j.actbio.2019.11.015.

\section{References}

[1] S.W. O’Driscoll, F.W. Keeley, R.B. Salter, Durability of regenerated articular cartilage produced by free autogenous periosteal grafts in major full-thickness defects in joint surfaces under the influence of continuous passive motion. A follow-up report at one year, J. Bone Joint Surgery Am. 70 (4) (1988) 595-606.
[2] L.L. Johnson, Arthroscopic abrasion arthroplasty historical and pathologic perspective: present status, Arthrosc. J. Arthrosc. Relat. Surg. Off. Publ. Arthrosc Assoc. North Am. Int. Arthrosc. Assoc. 2 (1) (1986) 54-69.

[3] F. Taraballi, G. Bauza, P. McCulloch, J. Harris, E. Tasciotti, Concise review: biomimetic functionalization of biomaterials to stimulate the endogenous healing process of cartilage and bone tissue, Stem. Cells Transl. Med. 6 (12) (2017) 2186-2196.

[4] J.R. Steadman, W.G. Rodkey, J.J. Rodrigo, Microfracture: surgical technique and rehabilitation to treat chondral defects, Clin. Orthop. Relat. Res. (391 Suppl) (2001) S362-S369.

[5] K.L. Wong, K.B. Lee, B.C. Tai, P. Law, E.H. Lee, J.H. Hui, Injectable cultured bone marrow-derived mesenchymal stem cells in varus knees with cartilage defects undergoing high tibial osteotomy: a prospective, randomized controlled clinical trial with 2 years' follow-up, Arthrosc. J. Arthrosc. Relat. Surg. Off. Publ. Arthrosc. Assoc. North Am. Int. Arthrosc. Assoc. 29 (12) (2013) 20202028.

[6] C.H. Jo, Y.G. Lee, W.H. Shin, H. Kim, J.W. Chai, E.C. Jeong, J.E. Kim, H. Shim, J.S. Shin, I.S. Shin, J.C. Ra, S. Oh, K.S. Yoon, Intra-articular injection of mesenchymal stem cells for the treatment of osteoarthritis of the knee: a proof-ofconcept clinical trial, Stem. Cells 32 (5) (2014) 1254-1266.

[7] S. Wakitani, M. Nawata, K. Tensho, T. Okabe, H. Machida, H. Ohgushi, Repair of articular cartilage defects in the Patello-Femoral joint with autologous bone marrow mesenchymal cell transplantation: three case reports involving nine defects in five knees, J. Tissue Eng. Regen. Med. 1 (1) (2007) 74-79.

[8] H. Nejadnik, J.H. Hui, E.P. Feng Choong, B.C. Tai, E.H. Lee, Autologous bone marrow-derived mesenchymal stem cells versus autologous chondrocyte implantation: an observational cohort study, Am. J. Sports Med. 38 (6) (2010) $1110-1116$

[9] A. Gobbi, S. Chaurasia, G. Karnatzikos, N. Nakamura, Matrix-Induced autologous chondrocyte implantation versus multipotent stem cells for the treatment of large patellofemoral chondral lesions: a nonrandomized prospective trial, Cartilage 6 (2) (2015) 82-97.

[10] W. Wei, J. Luo, Thoughts on chemistry, manufacturing, and control of cell therapy products for clinical application, Hum. Gene Ther. (2018).

[11] F. Qu, Q. Li, X. Wang, X. Cao, M.H. Zgonis, J.L. Esterhai, V.B. Shenoy, L. Han, R.L. Mauck, Maturation state and matrix microstructure regulate interstitial cell migration in dense connective tissues, Sci. Rep. 8 (1) (2018) 3295

[12] E.A. Makris, R.F. MacBarb, N.K. Paschos, J.C. Hu, K.A. Athanasiou, Combined use of chondroitinase-ABC, TGF-beta1, and collagen crosslinking agent lysyl oxidase to engineer functional neotissues for fibrocartilage repair, Biomaterials 35 (25) (2014) 6787-6796.

[13] P.K. Bos, N. Kops, J.A. Verhaar, G.J. van Osch, Cellular origin of neocartilage formed at wound edges of articular cartilage in a tissue culture experiment, Osteoarthr. Cartil. 16 (2) (2008) 204-211.

[14] C.H. Lee, J.L. Cook, A. Mendelson, E.K. Moioli, H. Yao, J.J. Mao, Regeneration of the articular surface of the rabbit synovial joint by cell homing: a proof of concept study, Lancet 376 (9739) (2010) 440-448.

[15] A.J. Roelofs, J. Zupan, A.H.K. Riemen, K. Kania, S. Ansboro, N. White, S.M. Clark, C. De Bari, Joint morphogenetic cells in the adult mammalian synovium, Nat. Commun. 8 (2017) 15040.

[16] Y. Yu, M.J. Brouillette, D. Seol, H. Zheng, J.A. Buckwalter, J.A. Martin, Use of recombinant human stromal cell-derived factor 1alpha-loaded fibrin/hyaluronic acid hydrogel networks to achieve functional repair of full-thickness bovine articular cartilage via homing of chondrogenic progenitor cells, Arthritis Rheumatol. 67 (5) (2015) 1274-1285.

[17] J.A. Burdick, R.L. Mauck, J.H. Gorman 3rd, R.C. Gorman, Acellular biomaterials: an evolving alternative to cell-based therapies, Sci. Transl. Med. 5 (176) (2013) $176 \mathrm{ps} 4$.

[18] I.K. Ko, S.J. Lee, A. Atala, J.J. Yoo, In situ tissue regeneration through host stem cell recruitment, Exp. Mol. Med. 45 (2013) e57.

[19] M. Abbas, M. Alkaff, A. Jilani, H. Alsehli, L. Damiati, M. Kotb, M. Abdelwahed, F. Alghamdi, G. Kalamegam, Combination of mesenchymal stem cells, cartilage pellet and bioscaffold supported cartilage regeneration of a full thickness articular surface defect in rabbits, Tissue Eng. Regen. Med. 15 (5) (2018) 661-671.

[20] L.A. Solchaga, J.S. Temenoff, J. Gao, A.G. Mikos, A.I. Caplan, V.M. Goldberg, Repair of osteochondral defects with hyaluronan- and polyester-based scaffolds, Osteoarthr. Cartil. 13 (4) (2005) 297-309.

[21] C.W. Ha, Y.B. Park, J.Y. Chung, Y.G. Park, Cartilage repair using composites of human umbilical cord blood-derived mesenchymal stem cells and hyaluronic acid hydrogel in a minipig model, Stem. Cells Transl. Med. 4 (9) (2015) 1044-1051.

[22] Y. Zhao, H. Yan, S. Qiao, L. Zhang, T. Wang, Q. Meng, X. Chen, F.-.H. Lin, K. Guo, C. Li, W. Tian, Hydrogels bearing bioengineered mimetic embryonic microenvironments for tumor reversion, J. Mater. Chem. B 4 (37) (2016) 6183-6191.

[23] Z. Li, K.M. Kaplan, A. Wertzel, M. Peroglio, B. Amit, M. Alini, S. Grad, A. Yayon, Biomimetic fibrin-hyaluronan hydrogels for nucleus pulposus regeneration, Regen. Med. 9 (3) (2014) 309-326.

[24] M. Kurisawa, J.E. Chung, Y.Y. Yang, S.J. Gao, H. Uyama, Injectable biodegradable hydrogels composed of hyaluronic acid-tyramine conjugates for drug delivery and tissue engineering, Chem. Commun. (Camb.) (34) (2005) 4312-4314.

[25] F. Lee, J.E. Chung, M. Kurisawa, An injectable hyaluronic acid-tyramine hydrogel system for protein delivery, J. Control. Release Off. J. Control. Release Soc. 134 (3) (2009) 186-193.

[26] K.S. Kim, S.J. Park, J.A. Yang, J.H. Jeon, S.H. Bhang, B.S. Kim, S.K. Hahn, Injectable hyaluronic acid-tyramine hydrogels for the treatment of rheumatoid arthritis, Acta Biomater. 7 (2) (2011) 666-674. 
[27] W.S. Toh, M. Spector, E.H. Lee, T. Cao, Biomaterial-mediated delivery of microenvironmental cues for repair and regeneration of articular cartilage, Mol. Pharm. 8 (4) (2011) 994-1001.

[28] W.S. Toh, T.C. Lim, M. Kurisawa, M. Spector, Modulation of mesenchymal stem cell chondrogenesis in a tunable hyaluronic acid hydrogel microenvironment, Biomaterials 33 (15) (2012) 3835-3845.

[29] S.H. Park, J.H. Cui, S.R. Park, B.H. Min, Potential of fortified fibrin/hyaluronic acid composite gel as a cell delivery vehicle for chondrocytes, Artif. Organs. 33 (6) (2009) 439-447.

[30] C. Loebel, M. D’Este, M. Alini, M. Zenobi-Wong, D. Eglin, Precise tailoring of tyramine-based hyaluronan hydrogel properties using DMTMM conjugation, Carbohydr. Polym. 115 (2015) 325-333.

[31] P.J. Flory, in: Principles of Polymer Chemistry, Cornell University Press, Ithaca, 1953, p. 1953.

[32] E. Marsano, S. Gagliardi, F. Ghioni, E. Bianchi, Behaviour of gels based on (hydroxypropyl) cellulose methacrylate, Polymer (Guildf) 41 (21) (2000) 7691-7698.

[33] C. Xu, Y.K. Poh, I. Roes, E.D. O’Cearbhaill, M.E. Matthiesen, L. Mu, S.Y. Yang, D. Miranda-Nieves, D. Irimia, J.M. Karp, A portable chemotaxis platform for short and long term analysis, PLoS One 7 (9) (2012) e44995.

[34] V.E. Santo, A.M. Frias, M. Carida, R. Cancedda, M.E. Gomes, J.F. Mano, R.L. Reis, Carrageenan-based hydrogels for the controlled delivery of PDGF-BB in bone tissue engineering applications, Biomacromolecules 10 (6) (2009) 1392-1401.

[35] E. Farrell, O.P. van der Jagt, W. Koevoet, N. Kops, C.J. van Manen, C.A. Hellingman, H. Jahr, F.J. O’Brien, J.A. Verhaar, H. Weinans, G.J. van Osch, Chondrogenic priming of human bone marrow stromal cells: a better route to bone repair? Tissue Eng. Part C Methods 15 (2) (2009) 285-295.

[36] M.L. de Vries-van Melle, E.W. Mandl, N. Kops, W.J. Koevoet, J.A. Verhaar, G.J. van Osch, An osteochondral culture model to study mechanisms involved in articular cartilage repair, Tissue Eng. Part C Methods 18 (1) (2012) 45-53.

[37] J.M. Lee, B.S. Kim, H. Lee, G.I. Im, In vivo tracking of mesechymal stem cells using fluorescent nanoparticles in an osteochondral repair model, Mol. Ther. J. Am. Soc. Gene Ther. 20 (7) (2012) 1434-1442.

[38] F. Qu, M.P. Pintauro, J.E. Haughan, E.A. Henning, J.L. Esterhai, T.P. Schaer, R.L. Mauck, M.B. Fisher, Repair of dense connective tissues via biomaterial-mediated matrix reprogramming of the wound interface, Biomaterials 39 (2015) 85-94.

[39] S. Breslin, L. O'Driscoll, Three-dimensional cell culture: the missing link in drug discovery, Drug. Discov. Today 18 (5-6) (2013) 240-249.

[40] J. Baier Leach, K.A. Bivens, C.W. Patrick Jr., C.E. Schmidt, Photocrosslinked hyaluronic acid hydrogels: natural, biodegradable tissue engineering scaffolds, Biotechnol. Bioeng. 82 (5) (2003) 578-589.

[41] B.H. Wang, G. Campbell, Formulations of polyvinyl alcohol cryogel that mimic the biomechanical properties of soft tissues in the natural lumbar intervertebral disc, Spine 34 (25) (2009) 2745-2753.

[42] E. Pfeiffer, S.M. Vickers, E. Frank, A.J. Grodzinsky, M. Spector, The effects of glycosaminoglycan content on the compressive modulus of cartilage engineered in type ii collagen scaffolds, Osteoarthr. Cartil. 16 (10) (2008) 1237-1244.

[43] N. Davidenko, C.F. Schuster, D.V. Bax, R.W. Farndale, S. Hamaia, S.M. Best, R.E. Cameron, Correction to: evaluation of cell binding to collagen and gelatin: a study of the effect of 2D and 3D architecture and surface chemistry, J. Mater. Sci. Mater. Med. 29 (4) (2018) 39.

[44] D. Petta, A.R. Armiento, D. Grijpma, M. Alini, D. Eglin, M. D’Este, 3D bioprinting of a hyaluronan bioink through enzymatic-and visible light-crosslinking, Biofabrication 10 (4) (2018) 044104.

[45] D. Li, J. Zhou, F. Chowdhury, J. Cheng, N. Wang, F. Wang, Role of mechanical factors in fate decisions of stem cells, Regen. Med. 6 (2) (2011) 229-240.

[46] I.E. Erickson, A.H. Huang, S. Sengupta, S. Kestle, J.A. Burdick, R.L. Mauck, Macromer density influences mesenchymal stem cell chondrogenesis and maturation in photocrosslinked hyaluronic acid hydrogels, Osteoarthr. Cartil. 17 (12) (2009) 1639-1648.
[47] E. Farrell, S.K. Both, K.I. Odorfer, W. Koevoet, N. Kops, F.J. O’Brien, R.J. Baatenburg de Jong, J.A. Verhaar, V. Cuijpers, J. Jansen, R.G. Erben, G.J. van Osch, Invivo generation of bone via endochondral ossification by in-vitro chondrogenic priming of adult human and rat mesenchymal stem cells, BMC Musculoskelet. Disord. 12 (2011) 31.

[48] L. Bian, C. Hou, E. Tous, R. Rai, R.L. Mauck, J.A. Burdick, The influence of hyaluronic acid hydrogel crosslinking density and macromolecular diffusivity on human MSC chondrogenesis and hypertrophy, Biomaterials 34 (2) (2013) 413-421.

[49] Q. Jin, G. Wei, Z. Lin, J.V. Sugai, S.E. Lynch, P.X. Ma, W.V. Giannobile, Nanofibrous scaffolds incorporating PDGF-BB microspheres induce chemokine expression and tissue neogenesis in vivo, PLoS One 3 (3) (2008) e1729.

[50] Y. Deng, A.X. Sun, K.J. Overholt, G.Z. Yu, M.R. Fritch, P.G. Alexander, H. Shen, R.S. Tuan, H. Lin, Enhancing chondrogenesis and mechanical strength retention in physiologically relevant hydrogels with incorporation of hyaluronic acid and direct loading of TGF-beta, Acta Biomater. 83 (2019) 167-176.

[51] K. Duval, H. Grover, L.H. Han, Y. Mou, A.F. Pegoraro, J. Fredberg, Z. Chen, Modeling physiological events in 2D vs. 3D cell culture, Physiology (Bethesda) 32 (4) (2017) 266-277.

[52] M.L. de Vries-van Melle, R. Narcisi, N. Kops, W.J. Koevoet, P.K. Bos, J.M. Murphy, J.A. Verhaar, P.M. van der Kraan, G.J. van Osch, Chondrogenesis of mesenchymal stem cells in an osteochondral environment is mediated by the subchondral bone, Tissue Eng. Part A 20 (1-2) (2014) 23-33.

[53] W. Hayen, M. Goebeler, S. Kumar, R. Riessen, V. Nehls, Hyaluronan stimulates tumor cell migration by modulating the fibrin fiber architecture, J. Cell. Sci. 112 (Pt 13) (1999) 2241-2251

[54] R.D. LeBoeuf, R.H. Raja, G.M. Fuller, P.H. Weigel, Human fibrinogen specifically binds hyaluronic acid, J. Biol. Chem. 261 (27) (1986) 12586-12592.

[55] J. Lam, N.F. Truong, T. Segura, Design of cell-matrix interactions in hyaluronic acid hydrogel scaffolds, Acta Biomater. 10 (4) (2014) 1571-1580.

[56] A. Lolli, R. Narcisi, E. Lambertini, L. Penolazzi, M. Angelozzi, N. Kops, S. Gasparini, G.J. van Osch, R. Piva, Silencing of antichondrogenic microrna-221 in human mesenchymal stem cells promotes cartilage repair in vivo, Stem Cells 34 (7) (2016) 1801-1811.

[57] A. Lolli, F. Colella, C. De Bari, G. van Osch, Targeting anti-chondrogenic factors for the stimulation of chondrogenesis: a new paradigm in cartilage repair, J. Orthop. Res. Off. Publ. Orth. Res. Soc. 37 (1) (2018) 12-22.

[58] G. Knutsen, J.O. Drogset, L. Engebretsen, T. Grontvedt, TC. Ludvigsen, S. Loken, E. Solheim, T. Strand, O. Johansen, A randomized multicenter trial comparing autologous chondrocyte implantation with microfracture: long-Term follow-up at 14 to 15 years, J. Bone Joint Surg. Am. 98 (16) (2016) 1332-1339.

[59] J. Ng, Y. Wei, B. Zhou, S. Bhumiratana, A. Burapachaisri, E. Guo, G. Vunjak-Novakovic, Ectopic implantation of juvenile osteochondral tissues recapitulates endochondral ossification, J. Tissue Eng. Regen. Med. 12 (2) (2018) 468-478.

[60] M.L. Vainieri, D. Wahl, M. Alini, G, van Osch, S. Grad, Mechanically stimulated osteochondral organ culture for evaluation of biomaterials in cartilage repair studies, Acta Biomater. 81 (2018) 256-266.

[61] A.R. Armiento, M.J. Stoddart, M. Alini, D. Eglin, Biomaterials for articular cartilage tissue engineering: learning from biology, Acta Biomater. 65 (2018) 1-20.

[62] A. Lolli, L. Penolazzi, R. Narcisi, G. van Osch, R. Piva, Emerging potential of gene silencing approaches targeting anti-chondrogenic factors for cell-based cartilage repair, Cell. Mol. Life Sci. CMLS 74 (19) (2017) 3451-3465.

[63] B.M. Baker, R.P. Shah, A.H. Huang, R.L. Mauck, Dynamic tensile loading improves the functional properties of mesenchymal stem cell-laden nanofiber-based fibrocartilage, Tissue Eng. Part A 17 (9-10) (2011) 1445-1455. 